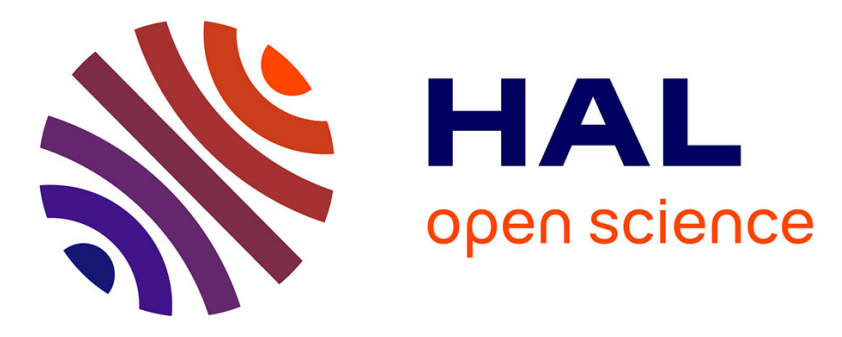

\title{
Regulated cell death and adaptive stress responses
}

Lorenzo Galluzzi, José Manuel Bravo-San Pedro, Oliver Kepp, Guido Kroemer

\section{To cite this version:}

Lorenzo Galluzzi, José Manuel Bravo-San Pedro, Oliver Kepp, Guido Kroemer. Regulated cell death and adaptive stress responses. Cellular and Molecular Life Sciences, 2016, 10.1007/s00018-016-2209y . hal-01301985

\section{HAL Id: hal-01301985 https: / hal.sorbonne-universite.fr/hal-01301985}

Submitted on 13 Apr 2016

HAL is a multi-disciplinary open access archive for the deposit and dissemination of scientific research documents, whether they are published or not. The documents may come from teaching and research institutions in France or abroad, or from public or private research centers.
L'archive ouverte pluridisciplinaire HAL, est destinée au dépôt et à la diffusion de documents scientifiques de niveau recherche, publiés ou non, émanant des établissements d'enseignement et de recherche français ou étrangers, des laboratoires publics ou privés. 


\section{Regulated cell death and adaptive stress responses}

Lorenzo Galluzzi ${ }^{1,2,3,4,5, *}$, José Manuel Bravo-San Pedro ${ }^{1,2,3,4,5}$, Oliver Kepp, ${ }^{1,2,3,4,6}$ and Guido Kroemer $^{1,2,3,4,6,7,8, *}$

${ }^{1}$ Equipe 11 labellisée Ligue contre le Cancer, Centre de Recherche des Cordeliers, 75006 Paris, France; ${ }^{2}$ INSERM, U1138, 75006 Paris, France; ${ }^{3}$ Université Paris Descartes/Paris V, Sorbonne Paris Cité, 75006 Paris, France; ${ }^{4}$ Université Pierre et Marie Curie/Paris VI, 75006 Paris; ${ }^{5}$ Gustave Roussy Comprehensive Cancer Institute, 94805 Villejuif, France;

${ }^{6}$ Metabolomics and Cell Biology Platforms, Gustave Roussy Comprehensive Cancer Institute, 94805 Villejuif, France; ${ }^{7}$ Pôle de Biologie, Hopitâl Européen George Pompidou, AP-HP; Paris, France; ${ }^{8}$ Department of Women's and Children's Health, Karolinska University Hospital, 17176 Stockholm, Sweden.

*share senior co-authorship, to whom correspondence should be addressed at deadoc@vodafone.it (LG) or kroemer@orange.fr (GK)

Running title: Organization of cellular stress responses

Keywords: autophagy; apoptosis; ferroptosis; mitochondrial permeability transition; necrosis: necroptosis.

Author disclosure: The authors have no conflicts of interest to disclose. 


\begin{abstract}
Eukaryotic cells react to potentially dangerous perturbations of the intracellular or extracellular microenvironment by activating rapid (transcription-independent) mechanisms that attempt to restore homeostasis. If such perturbations persist, cells may still try to cope with stress by activating delayed and robust (transcription-dependent) adaptive systems, or they may actively engage in cellular suicide. This regulated form of cell death can manifest with various morphological, biochemical and immunological correlates, and constitutes an ultimate attempt of stressed cells to maintain organismal homeostasis. Here, we dissect the general organization of adaptive cellular responses to stress, their intimate connection with regulated cell death, and how the latter operates for the preservation of organismal homeostasis.
\end{abstract}




\section{Introduction}

One of the features that enabled life was the ability of primordial cells (or their precursor) to demarcate a portion of space within a semi-impermeable barrier, hence withdrawing themselves from the chemical and physical conditions that governed the (micro)environment while preserving a possibility to exchange molecules with it [1]. Such a partial confinement de facto established a primitive sort of homeostatic control, progressively allowing proto-cellular components, perhaps including ribozymes, to catalyze the first biochemical reactions and to self-propagate in an ever more controlled milieu [2]. Modern cells have evolved not only a highly refined version of that primordial barrier (the plasma membrane), but also sophisticated systems for the preservation of intracellular and extracellular homeostasis [3-6]. The pharmacological or genetic blockade of such mechanisms renders cells way more susceptible to succumb to relatively mild challenges, demonstrating that adaptive stress responses generally play crucial cytoprotective functions [4]. However, the acquisition of multicellularity (in its largest meaning) has brought about a superior need: the preservation of “supracellular” homeostasis. Thus, unicellular organisms that live in colonies, like Saccharomyces cerevisiae, respond to otherwise unbearable stress conditions (e.g., persistent nutrient deprivation) by activating a program of cellular suicide that involves most (but not all) cells, which de facto provides the surviving components of the colony with substrates that may ensure their survival [7-9]. Similarly, animal and plant cells that are unable to restore cellular homeostasis by means of adaptive stress responses actively commit suicide $[4,10]$. Such instances of regulated cell death (RCD) can manifest with various morphological, biochemical and immunological correlates [11-14], and constitute an ultimate attempt of stressed cells to preserve the integrity of the whole organism [15]. RCD preserves organismal homeostasis not only because it ensures the elimination of cells that have been damaged beyond recovery, but also because 
(stressed and) dying cells emit a wide panel of molecules that signal locally (via paracrine circuitries) and systemically (via endocrine circuitries) the state of danger.

Here, we discuss the general organization of cellular responses to stress, their intimate connection with various forms of RCD, and how the latter contribute to the maintenance of organismal homeostasis in modern eukaryotes. 


\section{Cellular responses to stress}

Modern eukaryotes are provided with a large panel of stress sensors, which constantly monitor indicators of intracellular or extracellular homeostasis, such as cytoplasmic ATP levels, growth factor availability, DNA stand breaks and oxygen tension $[16,17]$. Sensors of this type are present in virtually all subcellular compartments, depending on the conditions they are capable of detecting $[18,19]$. For instance, decreased ATP concentrations (which are paralleled by increased AMP levels), are sensed by the AMP-activated protein kinase (AMPK) complex, which is mostly localized to the cytosol [20, 21], whereas limited growth factor availability is detected at the outer leaflet of the plasma membrane, where various growth factor receptors are expressed [22, 23]. Stress sensors are responsible for the initiation of one or multiple signaling pathways that ultimately activate the mechanisms that execute adaptive stress responses. This can occur according to two functionally opposed paradigms. On the one hand, some sensors are constitutively turned off, and respond to perturbations of homeostasis with an increase in activity. This is the case of AMPK [20, 21]. On the other hand, some sensors are constitutively turned on, and respond to microenvironmental fluctuations with a decrease in activity. This is the case of various growth factor receptors, including the epidermal growth factor receptor (EGFR) [22, 23].

Irrespective of this distinction, stress sensors can operate at two distinct levels, generally depending on the duration of the (de)activating stimulus. On the one hand, they engage a signal transduction pathway that relies on (1) a ready-made molecular machinery, and (2) post-translational modifications only. This is important because it ensures a rapid reaction to stress. On the other hand, they initiate the synthesis of novel components of the molecular apparatus of response to stress, which is important to sustain cellular adaptation over time, if needed. Of note, such a delayed response is generally launched 
along with its rapid counterpart, yet comes into action only later, unless homeostasis has been restored in the meanwhile (Figure 1).

The DNA damage response mediated by the serine/threonine kinase ATM and tumor protein 53 (TP53, also known as p53) well exemplifies such an organization of adaptive responses to stress. ATM is recruited to DNA double-strand breaks by a multiprotein complex including MRE11 homolog A (MRE11A), nibrin (NBN) and RAD50 homolog (RAD50), where it becomes activated by trans- and auto-phosphorylation on S1981 [24]. Among various substrates, active ATM phosphorylates TP53 on S15 and checkpoint kinase 2 (CHEK2) on T68, resulting in the CHEK2-dependent phosphorylation of TP53 on S20 [24]. Phosphorylated TP53 has reduced affinity for the E3 ubiquitin protein ligase MDM2, and hence accumulates in the nucleus in the form of transcriptionally active tetramers [25, 26]. Since cytoplasmic p53 tonically inhibits autophagy by physically interacting with RB1-inducible coiled-coil 1 (RB1CC1), the accumulation of TP53 in the nucleus has two consequences: (1) it unleashes a rapid autophagic response that is required for the optimal handling of DNA damage [27, 28], and (2) alongside, it initiates the TP53-dependent synthesis of cell cycle-arresting proteins, like cyclin-dependent kinase inhibitor 1A (CDKN1A, best known as p2 $1^{\mathrm{Cip} 1}$ ), which allow the DNA repair machinery to operate [29, 30]. If DNA can be fully repaired, the activation state and expression levels of all these proteins return to baseline conditions, and the adaptive response to stress is shut down [25]. 


\section{Failing adaptation and regulated cell death}

Adaptive responses to stress are not always successful, and when homeostasis is irremediably lost the cell commits suicide. Interestingly, stress-induced RCD is generally triggered by the very same sensors that detect homeostatic perturbations, implying that such sensors are not only connected to the systems that attempt to repair damage and recover homeostasis, but also to the molecular machinery that controls RCD. This also indicated that there are molecular circuitries that operate as switches and de facto convert a cytoprotective signal into the induction of RCD (Figure 1). This situation is well exemplified by the cellular reaction initiated at the endoplasmic reticulum (ER) upon the accumulation of misfolded proteins, the so-called “unfolded protein response" (UPR) [5].

One important sensor of misfolded proteins in the ER lumen is heat shock 70kDa protein 5 (HSPA5, best known as GRP78 or BIP). In physiological conditions, GRP78 binds, hence inhibiting, various signal transducers of the ER membrane, including (but not limited to) eukaryotic translation initiation factor 2 alpha kinase 3 (EIF2AK3, best known as PERK) [6, 31]. As unfolded proteins accumulate, however, they compete with EIF2AK3 for GRP78 binding, resulting in PERK activation and the consequent phosphorylation of eukaryotic translation initiation factor 2 alpha (eIF2 $\alpha$ ) in the cytosol [32]. This causes a generalized arrest of Cap-dependent translation [33], coupled to the selective translation of mRNAs bearing internal ribosomal entry sites, including the mRNA coding for GRP78 itself [34], or exploiting alternative, upstream open-reading frames (ORFs), such as the mRNA encoding activating transcription factor 4 (ATF4) [35]. A reduced rate of protein translation combined with the increased availability of GRP78 may allow for the re-establishment of reticular homeostasis, a process that is marked by the dephosphorylation of eIF $2 \alpha$ and by the restoration of normal ATF4 levels [36]. Of note, eIF2 $\alpha$ dephosphorylation is also required for failing UPRs to emit an RCD-inducing 
signal [37]. In the latter case, however, the levels of ATF4 and other UPR-activated transcription factors like DNA-damage-inducible transcript 3 (DDIT3, best known as CHOP) remain elevated, resulting in overwhelming protein synthesis in the presence of dephosphorylated eIF2 $\alpha$ [38].

Interestingly, cellular stress sensors generally dispatch signals that actively inhibit RCD as cells attempt to restore homeostasis. However, when adaptation fails, such signals cease and cells succumb to RCD. Two models have been proposed to explain this phenomenon [39]. One possibility is indeed that stress sensors dispatch both RCD-inhibiting and RCD-inducing signals as soon as they are activated, and the latter overcome the former when adaptation fails. Another possibility is that stress sensors initially deliver only RCD-inhibiting signals, and when adaptation fails these are substituted by their RCDpromoting counterparts (Figure 2). Experimental arguments in clear favor of one model over the other are missing, and most likely they both apply (at least to some degree) in specific circumstances. Irrespective of the mechanisms whereby failing adaptation to stress initiates RCD, this also constitutes an adaptive response, but at the organismal level. 


\section{Regulated cell death and organismal homeostasis}

Cells in which adaptive stress responses have failed are damaged beyond recovery, and must be eliminated because (1) they have probably lost their function, and/or (2) they may constitute a threat to the entire organism. For instance, cells with unrepaired DNA are prone to accumulate somatic mutations as they divide, thereby standing at risk for malignant transformation [40]. It is therefore not surprising that cells from higher eukaryotes have evolved the capacity to commit suicide for the sake of organismal homeostasis [15]. However, this is not the only way whereby the transition from the adaptive arm of stress responses to the activation of RCD contributes to the maintenance of the entire organism. Indeed, both stressed and dying cells emit a large panel of signals that alert other cells of danger, including various cytokines and so-called "damage-associated molecular patterns” (DAMPs) [41-43].

This concept is well exemplified by viral infection. Virtually all cells respond to cytosolic doublestranded RNA and other nucleotides of microbial origin by producing elevated amounts of type I interferon (IFN) [44]. By binding to homodimeric or heterodimeric receptors on hitherto unaffected cells, type I IFN renders them relatively resistant to infection, hence exerting a crucial cytoprotective effect [44]. Moreover, type I IFN stimulates the synthesis of chemoattractants for T lymphocytes, such as chemokine (C-X-C motif) ligand 10 (CXCL10) [45]. After such a wave of type I IFN synthesis, infected cells often commit suicide, hence interrupting the viral cycle and limiting viral dissemination [46]. Moreover, cells succumbing to infection release several DAMPs, including ATP, mitochondrial DNA and the non-histone chromatin-binding protein high-mobility group box 1 (HMGB1) [47-49]. Altogether, these factors promote the activation of various myeloid and lymphoid cell populations, hence boosting the immunological protection of the entire organism against viral infection [50,51]. Thus, RCD contributes to the maintenance of organismal homeostasis in response to viral infection in 
several ways. Accordingly, several viruses have evolved strategies to manipulate the machinery that controls RCD to their benefit [46]. 


\section{Conclusions and perspectives}

Eukaryotic cells respond to stress by activating various systems that attempt to repair damage and restore cellular homeostasis while preventing RCD. When such responses fail, cells damaged beyond repair actively undergo RCD, which constitutes a mechanism for the maintenance of organismal homeostasis. It is becoming increasingly clear that preventing the regulated demise of post-mitotic cells is a difficult therapeutic objective [39]. Patients with ischemic or traumatic disorders, indeed, are generally treated hours after the initial perturbation of homeostasis, when a majority of affected cells have irremediably committed to die. Therapeutic interventions should therefore aim at protecting neighboring cells, which are still in the adaptive phase of the stress response, and/or at controlling the signals emitted by affected cells as they die [51, 52]. Such a therapeutic paradigm may maximize the benefit that ischemia and trauma patients obtain from treatment.

Acknowledgments: The authors are supported by the Ligue contre le Cancer (équipes labelisées); Agence National de la Recherche (ANR) - Projets blancs; ANR under the frame of E-Rare-2, the ERA-Net for Research on Rare Diseases; Association pour la recherche sur le cancer (ARC); Cancéropôle Ile-de-France; Institut National du Cancer (INCa); Fondation Bettencourt-Schueller; Fondation de France; Fondation pour la Recherche Médicale (FRM); the European Commission (ArtForce); the European Research Council (ERC); the LabEx Immuno-Oncology; the SIRIC Stratified Oncology Cell DNA Repair and Tumor Immune Elimination (SOCRATE); the SIRIC Cancer Research and Personalized Medicine (CARPEM); the Swiss Bridge Foundation, ISREC and the Paris Alliance of Cancer Research Institutes (PACRI). 


\section{Legends to Figures}

Figure 1. General organization of stress responses in modern eukaryotes. Eukaryotic cells generally respond to perturbations of intracellular or extracellular homeostasis by simultaneously activating a rapid mechanism of adaptation, relying on ready-made components and post-translational modifications, as well as a transcription-dependent system, which comes into action, if needed, to support adaptation over time. Alongside, stress sensors also dispatch signals that inhibit regulated cell death (RCD). If adaptation fails and homeostasis cannot be recovered, however, the signals dispatched by stress sensors become lethal, and cells undergo RCD.

Figure 2. Alternative models for the transition between the adaptive and lethal phase of stress responses. At least theoretically, failing stress responses can result in the activation of regulated cell death (RCD) via two mechanisms. A. Stress sensors initially dispatch RCD-inhibiting as well as RCDpromoting signals, and RCD intervenes when the latter overcome the former. B. Stress sensors initially dispatch RCD-inhibiting signals, which cease as adaptation fails. Alongside, stress sensors become able to dispatch RCD-promoting signals, which eventually cause RCD. 


\section{References}

[1] Lombard J, Lopez-Garcia P, Moreira D. The early evolution of lipid membranes and the three domains of life. Nat Rev Microbiol 2012;10:507-15.

[2] Orgel LE. The origin of life--a review of facts and speculations. Trends Biochem Sci 1998;23:491-5.

[3] Pearl LH, Schierz AC, Ward SE, Al-Lazikani B, Pearl FM. Therapeutic opportunities within the DNA damage response. Nat Rev Cancer 2015;15:166-80.

[4] Kroemer G, Marino G, Levine B. Autophagy and the integrated stress response. Mol Cell 2010;40:280-93.

[5] Hetz C. The unfolded protein response: controlling cell fate decisions under ER stress and beyond. Nat Rev Mol Cell Biol 2012;13:89-102.

[6] Hetz C, Chevet E, Harding HP. Targeting the unfolded protein response in disease. Nat Rev Drug Discov 2013;12:703-19.

[7] Carmona-Gutierrez D, Eisenberg T, Buttner S, Meisinger C, Kroemer G, Madeo F. Apoptosis in yeast: triggers, pathways, subroutines. Cell Death Differ 2010;17:763-73.

[8] Buttner S, Eisenberg T, Herker E, Carmona-Gutierrez D, Kroemer G, Madeo F. Why yeast cells can undergo apoptosis: death in times of peace, love, and war. J Cell Biol 2006;175:521-5.

[9] Madeo F, Herker E, Wissing S, Jungwirth H, Eisenberg T, Frohlich KU. Apoptosis in yeast. Curr Opin Microbiol 2004;7:655-60.

[10] Lam E. Controlled cell death, plant survival and development. Nat Rev Mol Cell Biol 2004;5:305-15.

[11] Galluzzi L, Vitale I, Abrams JM, Alnemri ES, Baehrecke EH, Blagosklonny MV, et al. Molecular definitions of cell death subroutines: recommendations of the Nomenclature Committee on Cell Death 2012. Cell Death Differ 2012;19:107-20. 
[12] Kroemer G, Galluzzi L, Vandenabeele P, Abrams J, Alnemri ES, Baehrecke EH, et al. Classification of cell death: recommendations of the Nomenclature Committee on Cell Death 2009. Cell Death Differ 2009;16:3-11.

[13] Kroemer G, Galluzzi L, Kepp O, Zitvogel L. Immunogenic cell death in cancer therapy. Annu Rev Immunol 2013;31:51-72.

[14] Kepp O, Senovilla L, Vitale I, Vacchelli E, Adjemian S, Agostinis P, et al. Consensus guidelines for the detection of immunogenic cell death. Oncoimmunology 2014;3:e955691.

[15] Fuchs Y, Steller H. Programmed cell death in animal development and disease. Cell 2011;147:742-58.

[16] Galluzzi L, Pietrocola F, Levine B, Kroemer G. Metabolic control of autophagy. Cell 2014;159:1263-76.

[17] Green DR, Galluzzi L, Kroemer G. Cell biology. Metabolic control of cell death. Science 2014;345:1250256.

[18] Galluzzi L, Bravo-San Pedro JM, Kroemer G. Organelle-specific initiation of cell death. Nat Cell Biol 2014;16:728-36.

[19] Sica V, Galluzzi L, Bravo-San Pedro JM, Izzo V, Maiuri MC, Kroemer G. Organelle-specific initiation of autophagy. Mol Cell 2015:IN PRESS.

[20] Hardie DG, Ross FA, Hawley SA. AMPK: a nutrient and energy sensor that maintains energy homeostasis. Nat Rev Mol Cell Biol 2012;13:251-62.

[21] Galluzzi L, Kepp O, Vander Heiden MG, Kroemer G. Metabolic targets for cancer therapy. Nat Rev Drug Discov 2013;12:829-46.

[22] Avraham R, Yarden Y. Feedback regulation of EGFR signalling: decision making by early and delayed loops. Nat Rev Mol Cell Biol 2011;12:104-17.

[23] Concha-Benavente F, Srivastava RM, Ferrone S, Ferris RL. EGFR-mediated tumor immunoescape: The imbalance between phosphorylated STAT1 and phosphorylated STAT3. Oncoimmunology 2013;2:e27215. 
[24] Shiloh Y, Ziv Y. The ATM protein kinase: regulating the cellular response to genotoxic stress, and more. Nat Rev Mol Cell Biol 2013;14:197-210.

[25] Kruiswijk F, Labuschagne CF, Vousden KH. p53 in survival, death and metabolic health: a lifeguard with a licence to kill. Nat Rev Mol Cell Biol 2015;16:393-405.

[26] Zirngibl K, Moll UM. p53 further extends its reach. Oncoimmunology 2013;2:e24959.

[27] Galluzzi L, Pietrocola F, Bravo-San Pedro JM, Amaravadi RK, Baehrecke EH, Cecconi F, et al. Autophagy in malignant transformation and cancer progression. EMBO J 2015;34:856-80.

[28] Maiuri MC, Galluzzi L, Morselli E, Kepp O, Malik SA, Kroemer G. Autophagy regulation by p53. Curr Opin Cell Biol 2010;22:181-5.

[29] Bieging KT, Attardi LD. Deconstructing p53 transcriptional networks in tumor suppression. Trends Cell Biol 2012;22:97-106.

[30] Bishehsari F, Gach JS, Akagi N, Webber MK, Bauer J, Jung BH. Anti-p21 autoantibodies detected in colorectal cancer patients: A proof of concept study. Oncoimmunology 2014;3:e952202.

[31] Harding HP, Zhang Y, Ron D. Protein translation and folding are coupled by an endoplasmicreticulum-resident kinase. Nature 1999;397:271-4.

[32] Kepp O, Semeraro M, Bravo-San Pedro JM, Bloy N, Buque A, Huang X, et al. eIF2alpha phosphorylation as a biomarker of immunogenic cell death. Semin Cancer Biol 2015;33:86-92.

[33] Siekierka J, Manne V, Ochoa S. Mechanism of translational control by partial phosphorylation of the alpha subunit of eukaryotic initiation factor 2. Proc Natl Acad Sci U S A 1984;81:352-6.

[34] Sarnow P. Translation of glucose-regulated protein 78/immunoglobulin heavy-chain binding protein mRNA is increased in poliovirus-infected cells at a time when cap-dependent translation of cellular mRNAs is inhibited. Proc Natl Acad Sci U S A 1989;86:5795-9.

[35] Vattem KM, Wek RC. Reinitiation involving upstream ORFs regulates ATF4 mRNA translation in mammalian cells. Proc Natl Acad Sci U S A 2004;101:11269-74. 
[36] Novoa I, Zeng H, Harding HP, Ron D. Feedback inhibition of the unfolded protein response by GADD34-mediated dephosphorylation of eIF2alpha. J Cell Biol 2001;153:1011-22.

[37] Boyce M, Bryant KF, Jousse C, Long K, Harding HP, Scheuner D, et al. A selective inhibitor of eIF2alpha dephosphorylation protects cells from ER stress. Science 2005;307:935-9.

[38] Han J, Back SH, Hur J, Lin YH, Gildersleeve R, Shan J, et al. ER-stress-induced transcriptional regulation increases protein synthesis leading to cell death. Nat Cell Biol 2013;15:481-90.

[39] Galluzzi L, Bravo-San Pedro JM, Vitale I, Aaronson SA, Abrams JM, Adam D, et al. Essential versus accessory aspects of cell death: recommendations of the NCCD 2015. Cell Death Differ 2015;22:58-73.

[40] Hanahan D, Weinberg RA. Hallmarks of cancer: the next generation. Cell 2011;144:646-74.

[41] Le Bert N, Lam AR, Ho SS, Shen YJ, Liu MM, Gasser S. STING-dependent cytosolic DNA sensor pathways regulate NKG2D ligand expression. Oncoimmunology 2014;3:e29259.

[42] Galluzzi L, Kepp O, Kroemer G. Mitochondria: master regulators of danger signalling. Nat Rev Mol Cell Biol 2012;13:780-8.

[43] Vacchelli E, Aranda F, Obrist F, Eggermont A, Galon J, Cremer I, et al. Trial watch: Immunostimulatory cytokines in cancer therapy. Oncoimmunology 2014;3:e29030.

[44] McNab F, Mayer-Barber K, Sher A, Wack A, O'Garra A. Type I interferons in infectious disease. Nat Rev Immunol 2015;15:87-103.

[45] Schoggins JW, Wilson SJ, Panis M, Murphy MY, Jones CT, Bieniasz P, et al. A diverse range of gene products are effectors of the type I interferon antiviral response. Nature 2011;472:481-5.

[46] Galluzzi L, Brenner C, Morselli E, Touat Z, Kroemer G. Viral control of mitochondrial apoptosis. PLoS Pathog 2008;4:e1000018.

[47] Krysko DV, Garg AD, Kaczmarek A, Krysko O, Agostinis P, Vandenabeele P. Immunogenic cell death and DAMPs in cancer therapy. Nat Rev Cancer 2012;12:860-75. 
[48] Kanegasaki S, Tsuchiya T. Alarmins released during local antitumor treatments play an essential role in enhancing tumor growth inhibition at treated and non-treated sites via a derivative of CCL3. Oncoimmunology 2014;3:e958956.

[49] Kaczmarek A, Vandenabeele P, Krysko DV. Necroptosis: the release of damage-associated molecular patterns and its physiological relevance. Immunity 2013;38:209-23.

[50] Spel L, Boelens JJ, Nierkens S, Boes M. Antitumor immune responses mediated by dendritic cells: How signals derived from dying cancer cells drive antigen cross-presentation. Oncoimmunology 2013;2:e26403.

[51] Workenhe ST, Mossman KL. Rewiring cancer cell death to enhance oncolytic viroimmunotherapy. Oncoimmunology 2013;2:e27138.

[52] Jiang H, Fueyo J. Healing after death: antitumor immunity induced by oncolytic adenoviral therapy. Oncoimmunology 2014;3:e947872. 


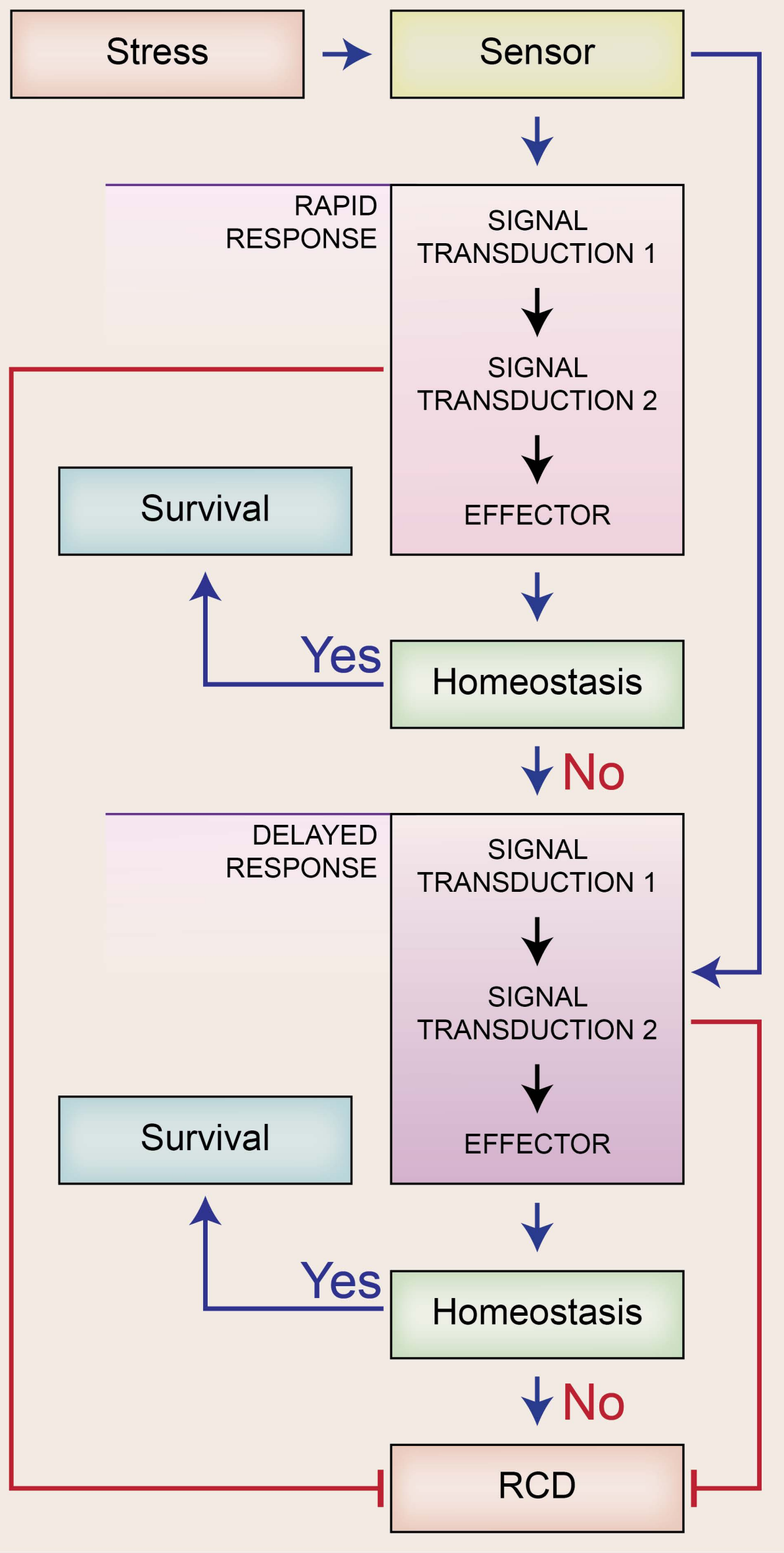

Figure 1 

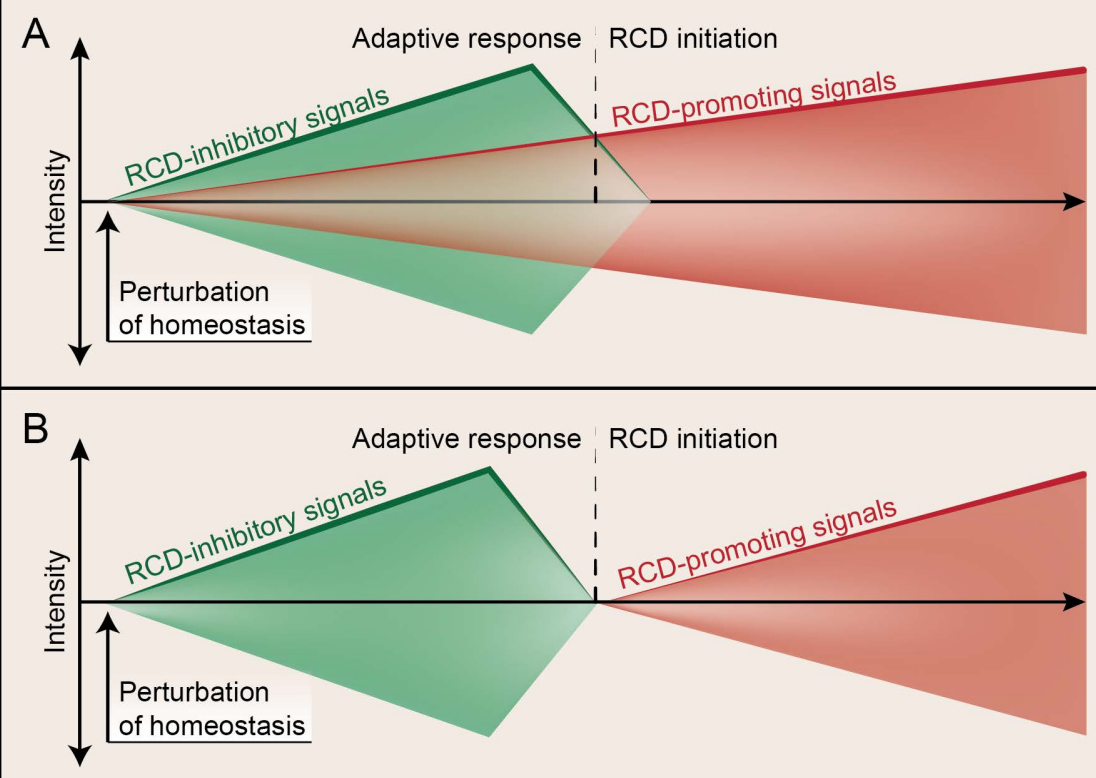

Figure 2 